\title{
DIE POSITIVERING VAN DIE ETIESE NORM*
}

Dit is nie die uitsluitlike voorreg en taak van die Etiek om hom oor die norme te besin nie. Omdat ons hele menslike bestaan vasgevang sit in die teenstelling tussen die feitelike en die normatiewe, die syn en die behore as gevolg van die verwoestende mag van die sonde, lê dit op die weg van elke wetenskap en in besonder die geesteswetenskap om hom deeglik te besin oor die norme wat op sy bepaalde gebied van toepassing is sowel as oor die norme wat algemeen van belang mag wees. In navolging van Windelband') kan ons onderskei tussen natuurwette wat nie oortreebaar is nie, maar wat nogtans opgespoor moet word, en norme wat wel oortreebaar is en wat die menslike verantwoordelikheid direk aanspreek.

Hierdie diskrepansie tussen die feitelike en die normatiewe, die syn en die behore word nog skerper in die lig gestel, meen ek, teen die lig van die Christelike lewens- en wêreld beskouing. En die Christelike wetenskap sal eers dan bewaar kan word teen skolastisisme en verstarring as dit sy profetiese taak van die ontdekking, blootlegging, interpretasie en formulering van die onderskeie norme met erns en oortuiging vervul.

Des te belangriker word hierdie taak omdat die sekularisme in sy huidige fase ' $\mathrm{n}$ storm rondom die norm ontketen het en met demoniese verfyndheid trag om die transendente oorsprong van norme te bevraagteken en sover dit die universiteit betref, in naam van wetenskaplikheid en objektiwiteit, die studie van die normatiewe af te skuif. En in die gesekulariseerde Weste is ook die universiteite in hierdie proses besig om lanseerbasisse te word wat geleide projektiele moet slinger teen die normatiewe en veral teen die Goddelike element in die normatiewe. Ook hierin mag die Christelike universiteit

- met sy georiënteerdheid aan die Christelike lewensbeskouing en normatiewe struktuur alleen te staan kom, maar hom desondanks nie van koers laat bring nie. En dan mag ons dit nie as die taak van teoloog en filosoof ${ }^{1 a}$ ) alleen beskou nie, maar van elke vakwetenskaplike, sosioloog, ekonoom ens.

Die storm rondom die norm is ook ontketen t.o.v. die

* Intreerede gelewer by die aanvaarding van 'n professoraat in Etiek en Logika aan die P.U. vir C.H.O., op 8 Maart 1968, deur prof. dr. B. Duvenage. 
sedelike lewe van die mens. Die sedelike ontaarding, verval of bestialiteit ruis met die krag van 'n tornado deur ons lewe en is besig om alle vastighede omver te werp. En die morele krisis is tot 'n groot mate die krisis van die sedelike norm. Die aftakeling van die sedelike normbesef maak die taak van die Christelike Etiek des te dringender, nl. om duidelike rigtingwysers te plant in die sedelike onsekerhede en om omgestote rigtingwysers weer op te tel as hulle in die verskuiwende situasie van belang kan wees.

\section{Probleemstelling:}

Met hierdie laaste sin het ons iets van die problematiek aan die lig laat kom. Ons wil dit graag nader aandui. Populêr gestel wil ons dan nader ondersoek instel na die verhouding tussen beginsel en praktyk. En dan is ons veral geïnteresseer in die vraag of norme algemeen en altyd geldend is en of hulle ook afgestem moet wees op die veranderende situasie. Dit is immers van weinig belang as die Calvinisme sou roem in sy sg. beginsels, maar as dié beginsels soos wolke hoog bo die werklikheid swewe. En as die Christelike Etiek wil ontkom aan die aanklag dat dit werklikheidsvreemd en onprakties is, is dit nodig dat hy hom besin oor die weg waartoe ons uit die beginsel tot die konkrete toepassing moet kom. En dit is hier waar die positivering van die norm in die prentjie kom. In die positiveringsproses gaan dit juis om die opsporing en formulering van die norm in sy betrokkenheid op 'n konkrete en individuele situasie.

Ons kan vragenderwys ons probleemstelling as volg uitbrei. Is die Christelike Etiek alleen prinsipiële Etiek of kan dit terselfdertyd situasionele en eksistensiële Etiek wees? Moet die tradisionele toepassing van 'n beginsel as normatief gereken word?

Nadere begripsbepaling:

Dit is nodig om die begrippe-apparaat waarmee ons hier opereer nader aan te dui. Die woord "norm" is afgelei van die Latynse norma wat maatstaf of rigsnoer beteken. 'n Norm dien dus om iets te beoordeel of te meet. Geesink omskryf die norm as ,de van onze willekeur onafhanklijke waardemeter voor het beoordelen van wat geldt en van wat behoort te gelden".") 
Die norm word dus maatstaf, gehanteer soos 'n skietlood. Dit dui die stand van die feitelike aan in verhouding tot die behore.

Maar hieruit is ook duidelik dat die norm gestandaardiseer moet wees. Net soos ' $n$ krom lineaal nie gebruik kan word om 'n reguit lyn te trek nie, so kan 'n foutiewe norm nie bepaal wat reg of verkeerd, goed of sleg is nie. ' $n$ Norm ontleen nou sy gesag, sy standaard, sy waarborg aan die beginsel

Maar daarmee is ons by ' $n$ tweede begrip wat ons aandag vra $n l$. beginsel. Onder beginsel verstaan ons die onherleibare grondslag wat bepalend, regulatief en standaardiserend teenoor die norm staan. En dan het ons hier die religieuse beginsel op die $00 \mathrm{~g}$, wat die radikale posisie aandui van die sentrum van die mens nl. sy hart. M.a.w. in die beginsel word die verhouding van die mens teenoor God verdiskonteer.

P. G. W. du Plessis spreek van di? eie-aard of sinkern van die sedelike as die etiese beginsel ${ }^{3}$ ) wat hy dan onoortreebaar ag en waarbinne die etiese norm moet funksioneer.

Ons verkies egter om te spreek van die etiese bepaaldheid of sinkern, omdat hieruit nie die etiese norme afgelei kan word en dit nie standaardiserend teenoor die etiese norme staan nie, maar alleen die gebied aandui waarbinne die etiese norme moet funksioneer. Ons vind sterker aansluiting by S. P. van der Walt, wat van die religieuse apriori as die beginsel spreek sodat daar per slot van rekening slegs twee religieuse beginsels is $\mathrm{nl}$. die geloof in God of in ' $\mathrm{n}$ afgod.')

Hierdie religiese beginsel vorm dan ook wat die norme i.c. die etiese norme betref die basislaag waarmee die norme i.c. die etiese norme moet korrespondeer. Terloops dien daarop gewys te word dat norm nie met waarde vereenselwig moet word nie. Waarde dui 'n kwalifikasie aan wanneer aan die gestelde norm beantwoord word al dan nie. Waarde dra nie in sigself ' $n$ behorenselement nie. Geen wonder dat dit as surrogaat vir norm onder die druk van die sekularisme populêr geword het nie.

Maar behalwe die beginsel en die norm kom daar by die positivering nog 'n derde komponent in gedrang, t.w. die konkrete werklikheid of situasie. Ons sou die positiveringsproses kon omskryf as die voortdurende poging om die normatiewe op die feitelike af te stem. Hierin merk ons nou iets van die ingewikkelde en komplekse aard van die positiveringspro. ses. Dit moet na ons mening begin by die religieuse beginsel 
as uitgangspunt, daarna beweeg dit na die norm wat uit die beginsel gestandaardiseer is en dit eindig by die opsporing, formulering en interpretasie van die norm met die oog op die konkrete situasie.

Hierdie positivering van norme is die taak van elke gesagsdraer t.o.v. sy bevoegdheidsterrein,") sodat ons 'n wye verskeidenheid van positiewe norme kry bv. gesinsnorme, bedryfsnorme, staatkundige en kerklike norme ens. Die soewereiniteit in eie kring van elke samelewingsverband word hierin duidelik erken. Maar behalwe hierdie struktuurnorme kom daar uit die religieuse beginsel as basislaag ook binne die verskillende strukture of verbande duidelik etiese norme na vore, en dit het daartoe gelei dat Schippers bv, aan die Etiek 'n grensfunksie toeken") en dat sommige van die Etiek 'n „Universalwissenschaft" gemaak het, 'n standpunt wat egter tot verwarring lei.

Oor die vervlegtheid van die sedelike met ander aspekte bv. die logiese, die juridiese, die estetiese gaan ons nie nou dieper in nie. Ons wil egter konstateer dat die norme vir hierdie en ander gebiede ook uit die religieuse beginsel hul waarborg en standaard moet ontvang en daarom sal die etiese norme wat uit dieselfde religieuse beginsel gestandaardiseer is vanselfsprekend met ander norme kan korreleer. M.a.w. die norme wat bv. geld vir die kuns sal, omdat dit uit die religieuse beginsel sy standaard ontvang nie, ook aanspreekbaar kan wees uit die etiese norm wat uit dieselfde religieuse beginsel gedra word. Nie alleen die interne norme maar ook eksterne norme het 'n woord mee te spreek.

Vervolgens moet ons nou let op die drie komponente wat in die positivering van die etiese norm 'n rol speel.

Ons let eers op die rol van die religieuse beginsel.

Agter die orde in die positiveringsproses wat ons tot dusver gestel het nl. van beginsel, oor norm tot konkrete toepassing, sit alreeds 'n sekere uitgangspunt, wat bepaal is deur ons religieuse beginsel of grondmotief, as voorwetenskaplike gegewe. Hierdie spesifieke orde is alles behalwe vanselfsprekend. Die integrasie van die religieuse beginsel in die Etiek spring duidelik in die oog wanneer ons die geskiedenis van die Etiek t.o.v. ons probleemstelling die revue laat passeer. Selfs die apostels van die sg. neutraliteit sal daaroor die oë moet uitvryf. 
In die verloop of die gang van die positiveringsproses meen ons dat die religieuse uitgangspunt selfs deurslaggewend is. Maar dit bepaal ook die bron waaruit die norme geput word, aangesien die beginsel die norm moet standaardiseer.

Sowel die bronbepaling as die metode om tot die konkrete positiewe norm te kom lê onder invloed van die religieuse uitgangspunt. Ons maak slegs 'n paar grepe uit die geskiedenis van die Etiek om dit nader aan te toon

Die kasuistiek is as metode deur die Rooms-Katolieke Moraal-Teologie hoog in die saal gelig reeds sedert die dae toe Ambrosius 'n Christelike bewerking van Cicero se De Officiis probeer het. Die kasuistiek wil 'n standaard etiese voorskrif uitreik vir gelyksoortige gevalle en wil dus sedelike patroon knip deur die verstand wat as konfeksiepakke diens kan doen. Maar in die natuurlike dinge word nou juis die natuurlike rede as uitgangspunt geneem en nie die Skrif nie. Die spanning tussen natuur en genade wreek hom hier in die positivering. So word bv. in die pouslike ensiklieke Rerum Novarum 1891 en Quadragessimo Anno 1931 oor die arbeidslewe gehandel met norme ontleen aan die natuur. Die kasuistiek lê in die lyn van die wettisisme wat die vernaamste van die wet, die liefde, vergeet.

Jongere Rooms-Katolieke teoloë soos Karl Rahner en Schillebeeckx probeer van die rigorisme van die kasuistiek as pastorale hulpmiddel wegkom, maar tog loer die ou genadenatuur skema weer telkens om die hoek. Rahner spreek van die Existentialnorm wat die behore bepaal vir die individu maar dit kom uit die natuur van die individu op.") Schillebeeckx weer soek na die akkomodasie van die Skrif aan die kultuurkringe of samelewingsverbande, soos Rothuizen tereg aantoon.") Cronin wil as oortuigde Thomis die norme aposteriories vind uit die ervaring en apriories vind „,by reasoning from the nature of the living thing (nature being the inner principle from which the faculties or appetites of a thing spring)":)

By die Lutherse teologie, die sg. Ordnungs-teologie, word die bronbepaling en die positivering van die etiese norme sterk bepaal deur die soteriologiese uitgangspunt. Hier kan ons verwys na Gogarten en Brunner. Gogarten gaan selfs so ver om die skeppingsordeninge met die wil van God te identifiseer sodat die feitelike werklikheid vir hom normatief word, soos Bolkesteyn 
betoog het. ${ }^{10}$ ) En die kritiek van Zwicker teen Brunner tref o.i. die kol, nl. dat Brunner te eensydig op die skepping en te weinig op die verlossing ingestel is.") Die dualisme van Luther tussen die wêreldlike regiment waar die geregtigheid geld en die geestelike regiment waar die liefde geld werk nog steeds hierin deur. Gevolglik word die skeppingsordeninge as bron van die norm verselfstandig.

Maar dit is veral die huidige eksistensie-etiek waarin die rol van die religieuse grondmotief na vore tree t.o.v. die bronbepaling en die metode van positivering. Anders as die medehumanis, Kant word daar nie uitgegaan van 'n kategoriese imperatief nie wat met 'n rigoristiese pligsbesef die mens onder die sweepslag van 'n „du sollst" aandryf nie. P. G. W. du Plessis het duidelik aangetoon dat die etiese as sodanig verval wanneer die etiese behore opgeskort word soos by sommige eksistensie-filosowe die geval is. ${ }^{12}$ )

In die jongste fase van die sekularisme meen Stoker 'n soeke na die vaste selfs die Goddelike te ontdek, maar dan immanent in die kosmos. ${ }^{13}$ ) Dit hang ten nouste saam met 'n moontlike religieuse grondmotief wat eie is an die huidige tyd en wat in die Etiek op pregnante wyse tot openbaring kom. Dit raak eers die orde van die positivering. Die huidige tendens is om die vaste en die sekere, die beginsel as waarborg vir die norm opsy te skuif. In die positiveringsproses moet dan nie die beginsel as uitgangspunt en rugsteun vir die positiewe norme geld nie. Maar uit die kontingente situasie, die hier en die nou, moet die mens al soekende op weg gaan na die vaste, die sin, die sekerheid. Die situasie dwing die mens tot optrede, en in sy op weg wees na die huis van die Syn moet die mens homself transendeer en selfrealiserend sy eie norme skep. Die beginsel word apriories afgeskryf en dit word as 'n immer wykende eindpunt êrens aan die horison gestel, maar eintlik is die beginsel vir dié nuwe etiek 'n lugspieëling wat jy nooit bereik nie.

Maar daarmee is ook wat die bronbepaling van die norm betref ' $n$ eie rigting ingegaan. Die bron van die norm lê dan in die eksistensie, nie in die beginsel nie, in die situasie eerder as in die vaste uitgangspunt. Natuurlik beteken dit dat die norm nie gestandaardiseer of geratifiseer kan word nie, omdat daar geen rugsteun van ' $n$ vaste beginsel is nie. Daarmee verval egter die norm as sodanig. Ons staan hierin by die konsekwen- 
sies van die ontkersteningsproses, die sekularisme, wat in sy pluralistiese fase alle lewensbeskouings gelykwaardig ag, nl. dat geeneen van belang is nie en daarom afgeskryf moet word Dit ontloop die hele vraag na die Waarheid.

In hierdie fase van die sekularisme is die bestemmingslose, losgeslane, voortploeterende mens besig om te soek na vastigheid, 'n immanente vastigheid. Hy wil met die tou om sy eie nek hom uit die put trek. En sy naels is tot in die bloed afgekrap teen die muur van sy geworpenheid waarin hy vooraf alle vasklouplekke uitgetrek het. Die rewolusie van die moraal is hierin onmenslik wreed omdat dit onder die kamouflage van vryheid, die mens verslaaf en telkens in die vuilisblik van sy sg. noodlotsbestemming terugwerp.

Vir ons doel is dit egter nie nodig om die wanhoop van hierdie eksistensie-etiek langer ten toon te stel nie. Dit is egter belangrik om te let op die rol wat die religieuse beginsel van die post-Christelike, post-ateïstiese sekularisme in hul etiek speel. So skryf Fletcher bv.:

„The new morality, situation ethics, declares that anything and everything is right or wrong, according to the situation".")

En verder: „For the situationist there are no rules none at all".'

En as P. Lehman dit toepas op die huwelik en geslagsgemeenskap kom hy tot die konklusie:

"It is not marriage which legitimizes the sexual act but the sexual act which legitimizes marriage". ${ }^{16}$ )

Dit is terselfdertyd uit die voorgaande duidelik waar die oorspronge van die huidige mini-moraal geleë is. Die vaste, die beginsel word geminimaliseer in die positiveringsproses en die losheid van binding aan die vaste word gemaksimaliseer. Die normatiewe, die behore moet dan nie in rekening gebring word nie.

Die Calvinistiese Etiek wil daarenteen uitgaan van die vaste, die religieuse beginsel in die positiveringsproses. En dan word hierdie beginsel aan die Skrif as besondere Openbaring ontleen. Dooyeweerd spreek van die Bybelse grondmotief in terme van skepping, sondeval en verlossing, wat dan in teenstelling met die buite-Bybelse grondmotiewe nie dialekties van aard is nie." ) Troost spreek van die Koninkryksethos,") met sy sentrerende rigting na God en sy spreidingsrigting na die geheel van die tydelike lewe. Persoonlik word ons ook 
die meeste aangespreek deur die Koninkryk van God as religieuse beginsel. Maar dan moet ons die Koninkryksgedagte nie slegs heilshistories bepaal nie, maar die soewereiniteit van God as Skepper en Herskepper van dic hele skepping daarin vergestalt sien. In die begrip Koninkryk sou ons die eenheid van skepping en verlossing tot sy reg kon laat kom. Verskillende beginsels kan uit hierdie primêre Beginsel afgelei word, bv. heerskappy van God, skeppingsbeginsel, sondebeginsel, herskeppingsbeginsel, verskeidenheids- en eenheidsbeginsel.

Ons wil in hierdie verband verwys na die roepingsbegrip soos dit deur Calvyn uit hierdie religieuse beginsel ontwerp is. Calvyn onderskei die Vocatio (met die hoofletter en die enkelvoud) van vocationes (meervoud). Eersgenoemde is die primêre allesbeheersende Roeping tot die Koninkryk waarin God die mens totaal in beslag neem. ${ }^{10}$ ) Luister hoe ondubbelsinnig Calvyn daaroor skryf:

„Regula prima omnium nostrarum actionum est sequi Deum vocantem" ${ }^{\prime \prime}$ ) (Die eerste reël vir al ons handelinge is om God wat roep te volg).

Uit hierdie allesbeheersende Roeping vloei nou verskillende roepinge voort t.o.v. die hele lewenswerklikheid.

Hierdie religieuse beginsel het 'n wetskant, wat daarin bestaan dat die hele werklikheid onder die heerskappy van God staan en dat God as Koning erken moet word. Dit beteken dat Hy sy wil aan ons bekend gemaak het in sy Woord as sy besondere openbaring en in die kosmos se strukture as sy algemene openbaring, en dit is hierdie wil wat in positiewe norme met die oog op die konkrete situasie gepositiveer moet word.

Maar hierdie religieuse beginsel het ook 'n subjeksy of 'n menslike kant. Die Koninkryk van God lê totaal beslag op sy burgers. Uit die „Total-anspruch" van die syn-in-die-Koninkryk of die syn-in-Christus vloei nuwe imperativi voort as positiewe norme. Thielicke druk dit soos volg uit:

„Ja, es bedeutet die totale Revision meiner Existenz in allen ihren Dimensionen, so gewiss Christus der Kosmokrator und nicht nur der Herr meiner Innerlichkeit ist".")

En Preisker spreek besielend van die „Hineingezogensein” uit die aangebroke en aanbrekende voleinding, wat terselfdertyd ook 'n „Hinausgezogensein" beteken. ${ }^{22}$ )

Maar ons moet terugkeer na die wetskant van die religieuse 
beginsel, om vervolgens die etiese norm as sodanig sterker onder die oog te vat.

Ons het reeds opgemerk dat die etiese norme uit ons standpunt hul standaardisering uit die religieuse beginsel van die Koninkryk moet ontvang. Die etiese norme wil nou die religieuse beginsel t.o.v. die sedelike bepaaldheid nader omlyn.

Maar om daartoe te kom is die besinning oor die bronne van die etiese norme vooraf noodsaaklik. Ons het reeds gewys op die Woord van God en die skeppingsordeninge as sodanige bronne. Maar dan moet ons laasgenoemde nie verselfstandig soos in die Ordnungs-teologie die geval is nie. Wurth waarsku teen die losmaak van die skeppingsordeninge van Christus, omdat dit tot 'n skeppingsideologie kan lei. ${ }^{23}$ )

En die eerste vraag wat dan hier na vore kom, is die vraag hoe ons die sedelike norme wat in die Skrif bekend gemaak is, moet bejeën. Onthou moet word dat die Bybel geen wetenskaplike handboek is nie, nie vir die ekonomie, of die politiek, die geskiedenis nie, en ook nie vir die Etiek nie. ${ }^{24}$ )

Maar tog is daarmee die direkte beroep op die Skrif nie uitgesluit nie. Die een beginsel van die Koninkryk word in 'n ryk gedifferensieerde aantal norme in die Skrif vir die verskillende lewensterreine na vore gedra. In die jongste tyd is daar in die Teologie druk gesprek aan die gang oor die sg. tydsbepaalde gesag van uitsprake in die Heilige Skrif. In dié verband word dan verwys na die sg. historiese verpakking waarin die gebooie tot ons kom en die eksistensie-teologie wil in sy etiek selfs die gesag van al sulke verpakte gebooie relativeer en soos die seremoniële wette van Levitikus behandel. Die sg. nuwe moraal-skool gaan weer die weg op om al die gebooie tot een groot gebod te herlei, maar dan word die toepassing van die een gebod van die liefde afhanklik gestel van die situasie. So is dit die geval by Robinson, Fletcher en selfs Preisker. Hoewel na ons mening die liefdesgebod die hoogste etiese norm is, moet dit in 'n gedifferensieerde veelheid uitgewerk word.

'n Ander weg word weer gevolg deur diegene wat aandring op die letterlike toepassing van die voorskrifte en gebooie in die Skrif ongeag die oorspronklike maatskaplike struktuur waarin hulle gestel is. Kuitert verwyt hierdie biblisisme dat dit nie die historiese verskuiwing verdiskonteer nie. ${ }^{x}$ )

Dit gaan hier inderdaad om die moeilike hermeneutiese 
probleem van voorskrifte en gebooie wat wel in 'n sekere tyd gegee is, maar waarvan die dieper sin nie tot dié tyd beperk is nie, veral dan as dit geratifiseer word aan die religieuse beginsel van die Koninkryk. So het bv. die Tien Gebooie ook 'n eie historiese inkleding as daar sprake is van die os en die esel in die Vierde en Tiende Gebooie, maar tog neem dit die dieper sin nie daarmee weg nie. Die paranese, die toepaslike verkondiging, die liefde moet tog steeds geldend bly. Ridderbos lê nadruk op die feit dat met die koms van Christus die Wet self onder 'n nuwe ,beoordelings-norm" gebring is..") Die Wet staan self in diens van die aangebroke en aanbrekende koninkryk as tugmeester na Christus en as lewensreël in die nuwe vaderland. Die nuwe skepping, die nuwe indikatief van die synin-Christus bring hierdie nuwe kanon, nuwe beoordelingsnorm met hom mee. ${ }^{2 \pi}$ ) Gevolglik is die kennis van die Wet nie die enigste en miskien nie die vernaamste toegang tot die kennis van die wil van God vir die konkrete lewensituasies. Ridderbos is van oordeel:

„dat heel de wet én heel het leven in het licht van het met Christus geopenbaarde heil moet worden verstaan en dat het inzicht in de wil van God voor de concrete levenssituaties niet minder van het geloof in Christus, het geleid worden door de Geest en de innerlijke vernieuwing van de mens afhankelijk is, dan van de kennis van de wet"." )

Maar ons religieuse beginsel van die Koninkryk van God beperk die bepaling van die bronne van die norme nie tot die besondere openbaring nie, maar bied ook opening vir die opsporing van norme in die skeppingsordeninge. Ons het reeds gewys op die gevaar van verselfstandiging van die skeppingsordeninge.

God het sy wette en ordinansies ook in die struktuur van die dinge ingeskape maar ons moet op ons hoede wees om dié wette en norme nie alleen deur struktuuranalise en fenomenologiese skou te probeer vind nie sonder korrelasie met die religieuse beginsel. Dit sou beteken dat ons die algemene openbaring wil lees sonder die bril van die besondere openbaring wat wel moontlik is, maar wat tot 'n skewe beeld, 'n vertekende beeld kan lei. Langs hierdie weg sou mens die huwelik as struktuur wou ondersoek om tot 'n normbepaling aangaande die huwelik te geraak, die metode wat juis gelei het in die Ord- 
nungs-teologie tot die verheffing van die feitelike tot aie normatiewe.

Die ander uiterste is die gevaar van onderskatting van die ordeninge en 'n reduksie van die normatiewe tot die persoonlike lewe. In die nuwe moraal-skool funksioneer hierdie metode dan so dat die liefde as hoogste norm geag word, maar dat die liefde vir sy funksionering selfs die ordeninge 'n belemmering kan vind. So sou die huwelik as instelling in die pad van die liefde tussen mense kan staan. Kuitert het in sy onlangse inougurele rede tereg die pleit gevoer vir die erkenning van die skepping as gegewe $e^{* y}$ ) waarby die institusionele en die personele tot hul reg kan kom, maar ons meen dan dat dit steeds weer uit die religieuse beginsel moet geskied waarin skepping en verlossing ten nouste verbind is.

Schrage stel dit soos volg:

„dass auch das aus der Schöpfung vernehmbare Gesetz durch das Evangelium nicht aufgehoben, sondern aufgerichtet wird". $)$

Ons meen dat die religieuse beginsel van die Koninkryk die Skriftuurlike norme en die skeppingsordeninge met hul norme in hul samehang stel. God se heerskappy is nie beperk tot die persoonlike lewe nie of selfs tot die Kerk as instituut nie maar is in Christus kosmies totalitêr. Sodanige reduksie van sy heerskappy is onskriftuurlik. Die skeppingsordeninge moet hul korreksie uit die Skriftuurlike norme ontvang, uit die religieuse beginsel. Die korreksie is nodig omdat ook die instellinge soos die huwelik en die staat onder die invloed van die sonde hul oorspronklike bestemming kan misloop en dit kan die fenomenologie nie aantoon nie.

Ons kom nou by die derde vlak in die positiveringsproses. Die eerste was die religieuse beginsel as basislaag. Daarna het ons die norme, i.c. die etiese norme se bronne afgetas. Nou moet ons kom tot die konkrete of positiewe norm.

Die positiveringsproses vind sy eindpunt in die toepassing van die norm op die enkele konkrete geval:" $)$ En daarom moet ons nou verder die weg vervolg hoe daar uit die Skriftuurlike norme en uit die skeppingsordeninge in die lig van die Skriftuurlike religieuse beginsel tot die positiewe norme gekom kan word.

Gesagsdraers moet immers uit die aangeduide bronne norme binne hul bevoegdheidsgrense opspoor en formuleer, en 
hierby moet die konkrete situasle in rekening gebring word. 'n Anachronistiese positivering wat nie rekening hou met die situasie nie, is eties van geen waarde nie. So sou ons bv. in die Wirtschaftethik nie met die Middeleeuse begrippe en situasies kan opereer nie asof ons nie in die 20e eeu leef nie. As die Christelike Etiek vandag sy dinamiek uit die Koninkryk van God wil laat deurtril moet dit ook situasionele, eksistensiële etiek wees, wat die mens in sy situasie aanspreek.

Maar die positivering is nou die werk van mense, feilbare mense. En dit bring mee dat verskillende faktore ' $n$ rol speel in die interpretasie en formulering van konkrete norme. Hieronder speel veral die volgende 'n rol: sedes, gewoontes, gebruike en dan die tradisionele interpretasie van norme.

Daarom moet ons duidelikheidshalwe onderskei tussen 'n konstante, 'n blywende komponent in die etiese normatiwiteit en ' $n$ veranderende, verskuiwende komponent.

$\mathrm{Na}$ ons mening is die konstante element te vind in die religieuse beginsel in die lig waarvan die Skriftuurlike norme of voorskrifte en die skeppingsordeninge gesien moet word. Die verskuiwende element het nou te doen met die toepassing daarvan in veranderende situasies. Die valse konserwatisme wil ook die tradisionele toepassing tot die blywende element verhef, maar dan word dit normatief, dan word die interpretasie en formulering normatief terwyl elke interpretasie op sy beurt deur 'n legio groep faktore bepaal word. Die progressivisme van die eksistensie-etiek wil die konstante element afskryf. Christelike etiek moet konservatief wees: die beginsel as blywende element; en progressief: aktuele toepassing van die beginsel.

Neem as voorbeeld die verskuiwing in die verhouding tussen die geslagte: As die positivering goed wil wees, moet die gehalte van die etiese norminhoud steeds afgeweeg word teen en onderskei word van die gehalte van tradisionele toepassing, sedes, gewoontes ens. Is dit suksesvolle positivering wanneer ouers bv. aan hul kinders sou sê: Toe ons opgesit het, was dit tot nege uur en dan in teenwoordigheid van die ouers en ook op twee stoele? In so 'n positivering speel die konstante element nie die deurslaggewende rol nie maar ' $n$ tradisionele toepassing. Ons meen dat ons moet begin by die vaste, die konstante om van daar na die konkrete te kom.

Maar daar duik ook nuwe situasies op waar geen tradisio- 
nele toepassing bestaan nie. Ons verwys na die etiese implikasies van orgaanoorplanting of na die etiek van die gebruik van kernwapens. Hier kan ons nie terugval op 'n gewoonte of gebruiklike toepassing nie. By die orgaanoorplanting moet ons dan uitgaan van die religieuse beginsel en die gestelde norme, die konstante element. Dit bring mee dat ons o.a. rekening moet hou met die feit dat die mens na die beeld van God geskape is, dat hy 'n geestelik-liggaamlike wese is, 'n eenheid met 'n eie persoonlikheid en identiteit, dat 'n vroegtydige dood van die skenker nie vergoed word of kan word deur die moontlikheid van 'n verlenging van die lewe by die ontvanger, dat die mens nie as proefkonyn gebruik kan word nie, dat die moontlikheid van persoonlikheidsverandering by sekere orgaanoorplantings kan geskied, bv. die brein ens.

Ons kan nie breedvoerig oor hierdie voorbeeld nou uitwei nie, maar wens alleen aan te toon dat die positivering van etiese norme in so 'n nuwe situasie van ons telkens vra om te begin by die vaste, die sekere en nie by die kontingente situasie nie.

In hierdie positiveringsproses speel egter nog 'n faktor 'n besonder belangrike rol, waarheen ons straks terloops verwys het. Ons het hier op die oog die onderskeidingsvermoë, die wysheid en in verband daarmee die leiding van God.

Dit is opmerklik dat in die Roomse Teologie besonder aandag aan die deug van die prudentia gegee is, waarskynlik om die rigorisme van die kasuistiek te bowe te kom. Thomas onderskei bv. drie momente nl. die consilium (beraadslaging), judicium (beoordeling) en praeceptum (voorskrif).

Wolfgang Schrage spreek van 'n ,erneuerte Urteilsfähigkeit" "2) en Ridderbos meen dat daar vir die kennis van die wil van God "de rechte innerlijke dispositie" aanwesig moet wees. $^{33}$ )

In die Ou Testament neem die begrip „chokma" 'n belangrike plek in. Veral in die Spreuke- en Prediker-boeke word die vrees van die Here die beginsel van die wysheid genoem, en daarin is verbind ook die gesonde tug in die opvoeding, asook insig en oorleg. In Psalm 119 word herhaaldelik gebid om die verstaan van die wet van die Here.

In die Nuwe Testament word die onderkenning van die wil van God verbind met die ware wysheid. Ons verwys hier na Ef. 5 : 15, 17: 
„Pasop dat julle nougeset wandel, nie as onwyse nie, maar as wyse. ... Daarom moet julle nie onverstandig wees nie, maar verstaan wat die wil van die Here is."

En in Fil. 1 : 9, 10 nog duideliker:

„En dit bid ek dat julle liefde nog meer en meer oorvloedig mag word in kennis en alle ervaring, om die dinge waar dit op aankom, te onderskei."

Van belang is hier die tà diaferonta - die wesenlike dinge, waarop dit aankom. En dit kan gevind word langs die weg van onderskeiding. Daarvoor gebruik Paulus die woord dokjmazein.

Hierdie selfde woord kom voor in Rom. $12: 2$, wat vir ons onderwerp van besondere belang geag kan word:

„En word nie aan hierdie wêreld gelykvormig nie, maar word verander deur die vernuwing van julle gemoed, sodat julle kan beproef wat die goeie en welgevallige en volmaakte wil van God is."

Aan hierdie beproef (dokimazein) gaan die metamorfose (die vernuwing) vooraf. Die indikatief van die syn-in-die koninkryk is bepalend vir die onderskeiding van dit waarop dit aankom en vir die onderkenning van die wil van God in die konkrete situasies, maar dit impliseer die aanlê van sekere maatstawwe of norme. Gevolglik kon Paulus in 1 Thess. 5 : 21 skryf: „Beproef alle dinge, behou die goeie", waarmee nie bedoel word dat alle dinge proefondervindelik ondersoek moet word nie, om dan daarna die goeie te behou nie, maar waarmee Paulus bedoel dat uit die vernuwing deur die Heilige Gees, die maatstaf van die wil van God teen alle dinge aangelê moet word. Schrage meen dat tot die dokimazein ook behoort:

„,in der konkreten Situation das überlieferte Wort recht anwenden zu können". ${ }^{34}$ )

Die leiding van die Heilige Gees om in die konkrete situasie die wil van God te doen bestaan dus nie in 'n nuwe openbaring wat direk bekend maak wat wel en wat nie gedoen moet word nie met uitskakeling van die menslike verantwoordelikheid. Dit bestaan in die vernuwing van die hele persoon, ook die nous (verstand) sodat met onderskeiding die wesentlike dinge (ta diaferonta) gevind kan word. 


\section{SAMEVATTING:}

Ons kan in die volgende punte die hooflyne saamvat:

1. Elke wetenskap, ook die Etiek, het aan 'n Christelike universiteit die taak om nie alleen deskriptiewe wetenskap te wees nie, maar ook normatiewe.

2. By die vasstelling van die norme vorm die religieuse beginsel van die Koninkryk van God 'n onontbeerlike basislaag.

3. Hierdie beginsel bepaal die bronne van die etiese norme asook die weg waarlangs die positiveringsproses hom moet voltrek.

4. As bronne vir die opsporing van die etiese norme geld die Skrif en die skeppingsordeninge as resp. besondere en algemene Openbaring van die Wil van God.

5. Die religieuse beginsel vorm die konstante komponent, terwyl die norme gepositiveer moet word met die oog op die situasie.

6. In hierdie proses speel die wysheid 'n pertinente rol. Die wysheid is meer as verstandelike insig maar is vrug van die Heilige Gees se werk in die gelowige.

\section{AANTEKENINGE:}

1) W. Windelband: Normen und Naturgesetze, in: Präludien, aangehaal deur G. Brillenburg Wurth: Het Christelijk Leven I, p. 33.

1a) Vgl. H. G. Stoker: Outlines of a Deontology of Scientific Method in Philosophy and Christianity.

2) W. Geesink: Gereformeerde Ethiek, I, p. 187.

3) P. G. W. du Plessis: Opskorting van die Etiese? D.Phil Proefskrif, Potchefstroom, p. 262.

4) S. P. van der Walt: Gods Wet en „die ander wet”, Potchefstroom p. 17.

5) Vgl. R. van Dyk: Mens en Medemens, Wageningen, p. 71

6) R. Schippers: Ethiek in Christelijke Encyclopedie, 2.

7) Vgl. A. Troost: Casuistiek en Situatie-ethiek, Utrecht, p. 286.

8) G. Th. Rothuizen: Bijbelse normen voor de sexualiteit? Geref. Weekblad, 8 Dec. 1967.

9) M. Cronin: The Science of Ethics, I, Dublin, 1920, p. 130 .

10) H. Bolkesteyn: Het $\mathrm{IK}-\mathrm{Gij}$ schema in de nieuwere philosophie en teologie, 1941, p. 77.

11) H. Zwicker: Reich Gottes, Nachfolge und Neuschöpung, Bern, p. 219

12) P. G. W. du Plessis: Opskorting van die etiese? p. 281 e.v

13) H. G. Stoker: Die eenheid van die wetenskap, Tydskrif vir wetenskap en kuns, Nov. 1967.

14) Fletcher, J.: Situation Ethics, London, p. 124

15) Idem: a.w., p. 55

16) P. Lehmann: Ethics in a Christian Context, London, p. 137.

17) H. Dooyeweerd: Verkenningen in de Wijsbegeerte..., in Perspectief

18) A. Troost: Casuïstiek en Situatie-ethiek, p. 375.

19) Vgl. W. J. Aalders: Roeping en beroep bij Calvijn, p. 16.

20) J. Calvini Opera Vol. XLIII, 208 (Baum, Cunitz, Reusz).

21) H. Thielicke: Theologische Ethik I, p. 68. 
22) H. Preisker: Das Ethos des Urchristentums, p. 45.

23) G. Brillenburg Wurth: Het Christelijk Leven, I, p. 65.

24) G. Th. Rothuizen: Bijbelse normen voor de sexualiteit? III, G.W., 22 Dec. 1967

25) H. Kuitert: Sociale Ethiek en geloof in Jezus Christus, Kampen, 1967, p. 34.

26) H. Ridderbos: Paulus, Kampen, 1967, p. 315.

27) H. Ridderbos: a.w., p. 316

28) H. Ridderbos: a.w., p. 317

29) H. M. Kuitert: a.w., p. 25, 29

30) W. Schrage: Die konkrete Einzelgebote in der paulinischen Paranese, Gerd Mohn, 1961, p. 212

31) R. van Dijk: Mens en Medemens, p. 63.

32) W. Schrage: a.w., p. 170.

33) H. Ridderbos: a.w., p. 318

34) W. Schrage: a.w., p. 169 